\title{
The Mixed Reality Toolkit as the Next Step in the Mass Customization Co-Design Experience
}

\author{
Frances Turner \\ Visiting Assistant Professor, Freeman College of Management, Bucknell University, Lewisburg, PA, USA, \\ frances.emme.turner@gmail.com \\ lan Welch \\ Class of 2018, Menlo College, Atherton, CA, USA, welch.aact@gmail.com
}

Received (10.12.2018.); Revised (10.05.2019); Accepted (23.05.2019.)

\begin{abstract}
The mass customization (MC) toolkit is the major enabler of relational value for consumers. Not a new concept, but nascent in the context of the MC co-design experience, mixed reality (MR) merges the real and virtual world. While the literature extols the significance of MR components - augmented reality (AR) and virtual reality (VR) - in manufacturing, $I T$, education and, to a limited extent, retail, few if any studies address its relevance to $M C$ and the consumer's perceived value of the co-design experience. Is a mixed reality configurator viable as the enabler of relational benefit in the consumer co-design experience? With visual and feedback features critical to the structure of successful webbased configurators, what characteristics must a MR toolkit possess to deliver optimal experiential value to the MC consumer? What is the nature of the MR toolkit and its bearing upon perceived complexity, control and enjoyment of the co-design process? Are these perceptions the most relevant to consider in designing a MC toolkit utilizing MR technology? This conceptual paper attempts to define a mixed reality toolkit and explore its potential influence on the consumer's perception of value of the MC co-design experience in the mixed reality context.
\end{abstract}

Key words: Co-design experience, configurator, mass customization, mixed reality, toolkit

\section{INTRODUCTION}

Scholars emphasize the principal enabler of consumer loyalty in mass customization (MC) is the toolkit or configurator [1]. Not a new concept, but nascent in the context of the MC co-design experience, mixed reality (MR) is "a class of experiences occurring in an ecosystem" [2] where real and virtual worlds merge via "physical and digital objects [that] co-exist and interact in real time" [3]. Few studies in the MC field address MR's relevance to the consumer's perceived value of the MC co-design experience. This conceptual paper begins to explore how a mixed reality toolkit - defined here as a MC configurator designed for use in mixed reality - might influence the consumer's relational value of $\mathrm{MC}$ and usher in the next step in shaping the MC codesign experience.

Technological advances continue to enable consumers and firms to interact with one another in a variety of ways, some very innovative [4], for a range of purposes via an assortment of platforms. As technology has paved the way for customization and personalization of offerings, it generates more individualized options, omnichannel interfaces and social connectedness that have yielded unprecedented growth in the importance of unique, experiential offerings beyond just products themselves $[5,6,7]$. "Markets of one", a single consumer who also comprises many markets within herself [8], open innovation [9], and the "hiring" of offerings by consumers to "do jobs" [10] have prompted even faster progressions of the evolution of consumer value. Today, the realities of experiences formerly dreamed of are becoming commercially viable. The augmented reality (AR) sector alone is valued at revenues ranging, if not exceeding, $\$ 60-\$ 120$ billion by 2020 in the consumer realm [11, 12], indicating the importance of understanding its impact on the consumer's MC experience. Scholars extol the significance of the MR components - augmented reality (AR) and virtual reality (VR) - in manufacturing, IT, education and training, tourism, medical and retail. Predicting future retail shopping centers morphing into consumer engagement spaces (CES), Brown and Lubelczyk [13] describe them as "rich experience hubs" or "physical spaces inside CES using immersive technologies ... VR, AR and MR to create unique environments that provide customers sophisticated multisensory experiences ... to touch and feel cocreated product and rich, deep content."

Considering extant literature on the elements integral to successful MC by provider and consumer $[14,15,16$, 17], several questions arise relative to our exploration. 
Is a mixed reality toolkit or configurator viable as, and a key enabler of, relational benefit in the consumer codesign experience as MC scholars have established the MC toolkit's importance to date? What characteristics must a MR toolkit possess to deliver optimal experiential value to the MC consumer? What is the nature of the MR toolkit and its bearing upon perceived complexity, control and enjoyment of the MC co-design process? Are these perceptions the most relevant to consider in designing a MC toolkit utilizing MR technology? Following, we attempt to address these questions. First, we contemplate the nature of the codesign experience in $\mathrm{MC}$ and the nature of the consumer's MR experience. Second, we consider the consumer's perception of value in MC and MR. Third, we discuss design elements of $\mathrm{MC}$ toolkits and what might be significant for a MR toolkit in the context of MC. Then, we consider some technologies that could afford the consumer the opportunity to engage in $\mathrm{MC}$ and how she might do so via MR. Last, we reflect upon implications of our conceptual exploration, posing ideas for research on what the future might hold regarding the consumer's value of the MC co-design experience in the context of MR.

\section{THE MC CO-DESIGN EXPERIENCE}

\subsection{The nature of the $M C$ co-design experience}

Pioneering studies introducing the concept of MC [18, 19] and its supply and operational capabilities [20] led to the next stage of extant work considering the consumer perspective. Studies focused on concepts such as product value, willingness-to-pay (WTP) and utility [21, 22, 23, 24, 25]. These evolved to exploration of motivations and perceptions of MC, such as aesthetic and functional fit, uniqueness, process effort, complexity, hedonic value, enjoyment, pride of authorship, creative achievement, control and others discovering further influences, costs and benefits of MC $[15,21,25,26,27,28,29,30]$. Ultimately, scholars identified two categories that form the foundation of consumer value of $\mathrm{MC}$, elements characteristically transactional or relational $[30,16]$. Franke and Schreier [26] described the former as the value of the MC outcome; while Franke and Piller [21] described the latter as the means by which the user experiences the co-design process, underscoring the part toolkit design plays, and asserting the MC toolkit as the major enabler of relational value.

Subsequent studies focused on key characteristics of toolkits or configurators effective in enhancing the consumer's perceived value of MC. These confirmed the nature of a successful MC experience for the consumer as the interaction between her and the tools she employed to engage in the customization of an offering [16, 30, 31, 32, 33, 34]. Collaboration between the consumer and firm via the co-design experience develops this partnership, but the consumer's use of the toolkit is what creates experiential value for her [30, 31, 32]. Well-designed toolkits are effective at benefitting the consumer by rendering a positive co-design experience [31]. They can be endowed with elements that enhance the MC process for the consumer, as well as influence the way the MC user perceives the codesign experience. The literature identifies several $M C$ toolkit experiential benefit-producing and cost-reducing features [15, 25, 26, 27, 28, 29, 32, 35, 36].

Further, the relationship between the firm and the consumer can be understood through exploration of the consumer's perception of the MC process and inform appropriate design of $\mathrm{MC}$ toolkits that provide rich, individual, loyalty-inducing experiences [31, 32, 35, 36]. Based upon the seminal work of Schreier [16], Dellaert and Dabholkar [15], and Merle et al. [30], Turner and Merle [31] empirically demonstrated the consumer's perceptions of complexity, control, and enjoyment of the co-design experience enhance the relationship between satisfaction with and loyalty intentions toward the online MC program. Literature on satisfaction, loyalty and their relationships to value support the importance of $\mathrm{MC}$ relational value, objectives and outcomes resulting from the interaction between the consumer and MC firm [37, $38,39]$. Complementing scholars' work on factors that comprise successful toolkit design $[14,15,32,35,36$, 40], Turner, Merle and Fatien [34] described scope of customization, feedback features and comparative elements as three categories MC toolkits should possess to enhance the consumer's perceived experiential value of the co-design process.

\subsection{The value of the MC co-design experience}

Scholarship on how the consumer perceives value from the MC experience reveal several benefits. Merle et al. [30] proposed five values, or perceived benefits, of MC utilitarian, uniqueness, self-expressiveness, hedonic, and creative-achievement. Moreover, subsequent studies by Trentin, Perin and Forza [33], Sandrin [35], and Sandrin, Trentin, Grosso and Forza [36] demonstrate the manner in which online sales configurators positively influence Merle et al.'s [30] list of customer perceived benefits derived from the $\mathrm{MC}$ experience.

Turner and Merle [31] supported the strong influence of the consumer's perception of complexity, control and enjoyment on the MC co-design experience and the relational values of satisfaction and loyalty intentions toward the MC program. They describe one cost, perceived complexity, the cognitive effort involved in how the consumer makes decisions, supporting the literature's designation of complexity as a hefty price the consumer pays for engaging in the collaborative design process $[15,25,28,30,32,41]$. The literature revealed mixed influences on perceived complexity, finding it exerts negative, positive or no effect depending upon the outcome tested [15, 28, 31].

A human being's desire for control over her environment is a potent force, too [14, 16, 31]. The ability of the MC consumer to master the subject at hand empowers control over the co-design experience [16]. Perceived control is "the extent to which consumers believe they are able to determine the outcome of the MC process" [15]. The user's perception of complexity erodes the sense of control over the codesign experience, but the use of the $\mathrm{MC}$ toolkit 
"enables the ability to focus on what's relevant"; and the degree of the individual's control during use of the toolkit dampens perceived complexity [15], yielding a positive impact on intent to use MC.

Perceived enjoyment is another benefit of the MC experience [31]. It is "pleasure associated with the experience of using" MC and "excitement" comes from the individual's ability "to compose [her] ideal product" $[15,30]$. A key factor in both brick-and-mortar and online shopping $[42,43]$, perceived enjoyment in the context of MC co-design generates entertainment value [16]. Realizing how enjoyment generates consumer value can help a provider build an effective MC toolkit [15]. Franke and Schreier [28] use the term "process enjoyment" to describe, "a positive affective reaction elicited by the process of self-designing the product." The design process itself fosters enjoyment and an emotional effect on the MC consumer as she collaborates actively in the co-design experience. Further, perceived enjoyment has a positive impact on intentions to use MC [15].

\section{THE MIXED REALITY EXPERIENCE}

\subsection{The nature of the MR experience}

Hardly new ideas, augmented, virtual and mixed reality have their commercial origins in aerospace in the 1990s [11]. We proceed to distinguish among each of the three concepts. The simplest description of AR is the merging of the virtual and real worlds [44] or the overlaying of digital images onto the physical world. An early definition of AR describes it as "integrat[ing] computer-generated objects with the real environment ... allow[ing] real-time interactions" [45] [46]. In Sholtz and Smith [47], AR "is the practice of displaying digital information over people's real-time view of objects, people, or spaces in the physical world". In all cases, the user should still be able to perceive and feel her surrounding physical environment while viewing digital images superimposed in front of her vision via an $A R$ device. Javornik [11] combines several scholars' descriptions connoting $\mathrm{AR}$ as "[o]verall ... the augmentation of the real with the virtual layer [via] computer-generated information [in] combination with interactivity." In the consumer space, AR is used in retail and promotional contexts to visualize and try on products, promote offers and interact with providers, engage in gaming, and access more detailed information on offerings. Consumer selection of digital images of items such as glasses, apparel and shoes are superimposed onto a user's body. Of the more oft used and vivid examples of this integration of both augmented and virtual reality are the hugely popular 2016 Pokémon Go game and IKEA's enabling of consumers to superimpose images of selected pieces of furniture in rooms in their homes to see how items look juxtaposed in a particular manner.

In virtual reality, the individual creates an alternate world or sense of being in an environment as if it was the physical world. Steuer [48] conceives VR in terms of presence and telepresence or "the sense of being in an environment, generated by natural or mediated means." One's surroundings are "temporally or spatially distant", like 3D or "an animated ... non-existent ... world synthesized by a computer" as in video games [48]. The virtual world is "populated by computer-generated objects which appear and behave as real" [49]. Generally, the VR user is completely cut off from reality with no incorporation of the actual surrounding environment. VR is any "experience ... in which the user is effectively immersed in a responsive virtual world ... [where] the user [exercises] dynamic control of [the] viewpoint" [50]. The user is in a created setting as exemplified in Linden Labs' VR offering, Second Life. Applications for VR include consumer video games and online shopping experiences where consumers try on apparel or accessories using a virtual try-on (VTO) mechanism. Further, VR is utilized in the development of "serious games" [51], applications and simulations used in education, healthcare, the military and corporate training, integrating entertainment, haptic and other human-centered concepts and designs to intensify senses of realness and immersion in order to improve the effectiveness of achieving organizational goals. Ultimately, a "virtual reality system initiates desired real-world actions in response to defined events occurring within a virtual environment" [52].

Milgram [53] defines mixed reality as an "environment in which real and virtual world objects are presented together within a single display" generating an experience that allows users to simultaneously interact with objects from the real world and the virtual world. MR is a range of "purely virtual environments to purely real environments" on opposite ends of a spectrum from augmented reality to virtual reality, respectively, and described as the "Reality-Virtuality (RV) continuum" [3]. Barba, Maclntyre and Mynatt [2] describe MR as "a class of experiences occurring in a ... socio-technical ecosystem" of perception beyond simple vision, places beyond space, and capabilities enabled by a variety of technologies. This broad conceptualization is based on the work of Mackay [54] who emphasizes MR as behaviorally relevant to a specific individual in a given context at a given time - an interesting intellection complementing the basic tenet of MC that the consumer gets exactly what she wants when she wants it [19].

\subsection{The value of the MR experience}

As noted, while the literature includes several studies on a variety of aspects of $V R, A R$ and $M R$, little research appears to exist examining and encompassing the combination of mass customization, MR and the codesign experience. Among those that do, Luh, Wang, Chang, J., Chang, S., and Chu [55] detail MC for children's shoe design enabled by AR. Merle, Senecal, and St.-Onge [56] present findings on virtual try-on platforms (VTO) in image interactivity technologies (IIT) and their effect on consumer response. McDonald and Golub [7] introduce the ELSE Corporation, a start-up company in Italy offering mass customization in a "Cloud SaaS API platform ... aimed at providing an extraordinary new customer shopping experience in $3 \mathrm{D}$ 
(... web and mobile apps, virtual reality, augmented reality and mixed reality environments) ... for the consumer goods, apparel and footwear industry [sic]". This is not to say that there are few explorations of the characteristics that describe the nature of VR, AR, MR and their impact on the consumer or individual. As referenced earlier, Second Life, Pokémon Go, IKEA and other companies use aspects of the reality spectrum in either consumer facing or industry applications for shopping, enriched product and service information, and a variety of consumer promotions [55]. Additionally, these providers extend the reach to and interaction with customers on individual and social bases [45, 46].

Scholars cite costs and benefits for consumers using augmented and virtual reality. From the consumer perspective, several are related to those revealed in studies on technology acceptance and the theory of planned behaviour, exploring concepts like telepresence, immersion and consumer innovativeness $[57,58]$. Many are in the realms of shopping and apparel retailing, marketing promotions, product information and gaming. Themes include self-efficacy, cognitive and affective effects, and attitude toward adoption. As stated earlier, of interest to our exploration are the experiential variables of perceived complexity, control, and enjoyment, and their relationship to the relational value of the $\mathrm{MC}$ consumer's co-design experience [31].

As in the MC literature, the AR experience involves the consumer's perception of complexity. AR provides more information on offerings making search mode easier, which heightens the feeling of ease of use [11]. On the other hand, this "information laden enriched" data on offerings in AR might be too much for the consumer and result in greater cognitive load [45,60]. Complexity is managed by the enjoyment brought by the experience, though for others the process is not perceived as difficult by users who enjoy thinking [58]. In addition, Merle et al. [56] noted, "VTO does not automatically lead to increases in ... cognitive responses".

Another MC experiential value, perceived control, corresponds in AR to the responsiveness of the medium enabling an MR experience and the reduction of risk [11]. The order of content presentation and, to an extent, ease of use, affect the consumer's sense of control [58]. AR enabling technology can be mobile. Employing mobile shopping experience as a proxy, a consumer's confidence increases with use, which heightens perception of control; the higher the user's innovativeness, the greater she perceives control [57]. Indeed, Dacko [59] writes that mobile augmented reality (MAR) "apps are seen as changing consumer behavior and are associated with increasingly high user valuations."

Like the MC co-design experience, AR offers enjoyment to the consumer by providing an entertaining experience $[11,46]$ via visual and $3 D$ renderings that contribute to and heighten enjoyment in this realm than in the real, physical world $[11,58]$. The AR environment is a "multisensory" [49] experience that is also playful and related to the perception of aesthetics [31, 59]. As noted earlier, consumers who like to think enjoy doing so in AR [49]. The environment is an "engaging, stimulating, pleasant" experience that generates enjoyment particularly when gamified [45]. Further, new technology and innovative features inherent in mobile AR provide enjoyment that encourages further use of mobile devices [59] with enjoyment increased for those who had more mobile shopping experience [57]. However, those with "indirect" or lower mobile shopping experience enjoyed the AR process less; and VTO did not necessarily increase affective reactions $[56,57]$.

\section{MASS CUSTOMIZATION AND MIXED REALITY}

\subsection{MC toolkit features that enhance the co- design experience}

As noted earlier, investigation of several outcome- and experience-related variables generated insights into the MC toolkit's key value-producing role for both the firm and consumer $[25,26,27,29,30 ; 32,33,35,36]$. Franke and Piller [1] determined toolkit design as significant because it enables and shapes the user's experience of MC's collaborative process, stressing the importance of the relationship between toolkit design, its value-rendering ability, consumer satisfaction and loyalty [31].

Subsequent studies provided several indications of the characteristics of a mass-customization toolkit that enhance the co-design experience [32, 34]. In their work on structuring sales configurators to avoid product variety paradox, Trentin et al. [33] proposed five capabilities that positively influence customer perceived benefits of the MC experience [32, 35, 36], specifically focused navigation, flexible navigation, easy comparison, user-friendly product-space description, and benefit-cost communication. With these studies in mind, we suggest three categories of MC toolkit design features [34]: scope of customization, feedback mechanisms, and comparative elements $[15,25,28$, 26, 29].

Scope of customization is the breadth and depth of design options and tools that the MC toolkit offers to create unique design experiences, utilizing a number of modules, range of options for each module and the degree of design freedom within and across the modules and options [34]. Large and structured to afford more selection, guided choices, flexibility and individual freedom, a well-designed scope of customization in a MC toolkit engenders ease of use to manage complexity and the cognitive cost of burden of choice $[14,15,25,26]$. The ability to choose from a plethora of well-managed choices not only increases perceived control of the MC process, but also enhances perceived enjoyment [15]. The MC toolkit "creates [the] entertainment process with larger solution spaces" spurring "joy of performing a creative or artistic act" [21]. Visualization mechanisms, variety and number of colors, designs, styles, ability to upload images, few design constraints, and autonomy to modify creations lead to greater perceived control $[15,29]$. The ability to adapt products in a less restricted, freer context further 
reduces consumer uncertainty associated with "virtual" transactions, while the interactivity yielded by the $\mathrm{MC}$ toolkit makes the act of adapting the MC offering more enjoyable [15].

The second toolkit design feature is feedback [34]. MC toolkits must offer interactive feedback to the consumer so she "visualize[s] and experience[s] customized products ... learn[ing] from the experience of others" [61]. The design should afford feedback and positive reinforcement to the co-designer during toolkit use in the forms of embedded and interpersonal feedback. The former is comprised of visual [15] and trial-anderror feedback integrated into the toolkit [14, 21, 29]. Both serve to decrease complexity while heightening control and enjoyment. Visual feedback helps the MC consumer get as close as possible to being able to examine her design even though she is unable to observe the offering physically [15]; and the feature must be present throughout the entire MC experience to produce and enhance perceived value for the user. Stage-by-stage visualization lowers uncertainty about next steps via "vivid mental images" [15] while showing progress through the co-design experience which prompts the sense of control. These vivid, visual cues enrich and immerse the consumer, creating an enjoyable co-design experience. Further, trial-and-error features are dynamic in that they help mitigate uncertainty through repeated experimentation while the user navigates, discovers and compares possible solutions. This experience permits the consumer to satisfy needs and wants as she customizes her unique offering from among a variety of options [14, 21]. Empirical work by Fürstner, Anišić, and Takács [62] emphasize the value of MC toolkits designed to adapt to knowledge and expertise levels of customers, further enhancing the individuality of the co-design experience. Interpersonal feedback features include those that foster requested assistance or counsel via the involvement others. Today, the growth and ubiquity of digital interactions through social media magnify the significance of interpersonal feedback. Blažek, Kolb, Streichsbier and Honetz [63] observed increases in social features in configurator designs. The work of Grosso, Forza and Trentin [64] has furthered understanding of the social dimensions of online toolkits. The social aspects inherent in user communities, input of peers, and assistance from company representatives enhance the MC consumer's perception of control and enjoyment while decreasing complexity $[15,29]$. The ability to see what others have co-designed helps the consumer bring her choices to reality, increases user-friendliness and lowers complexity [14]. In addition, the process provides a shared experience from seeing what others have accomplished during their own co-design experiences [27]. The opportunity to incorporate others' designs or use them as reference points and comparisons, as well as obtain peer input, decrease the MC consumer's perceived complexity by provoking "systematic ... favorable, problem-solving behavior" [27]. Positive peer and user contributions enhanced the MC consumer's enjoyment of the co-design experience.

Additionally, the means to get feedback from and "interact with trained customer representatives" contributed to the consumer's understanding of the toolkit and her creative options [27], helping her get closer to what she needs or prefers [34]. If interaction with a company representative is direct, "meaningful" and results in "immediate clarification of potential difficulties", perceived complexity declines [15]. This form of collaboration empowers and improves the individual's ability to create her co-design solution, increasing her control over the process. From a social perspective, if the interaction remains "cooperative in nature" throughout the MC experience [15], the result is enhanced enjoyment.

The third component of the MC co-design toolkit is comparative elements [34]. These allow the consumer to evaluate, compare and select combinations of options during the co-design experience $[25,32,33$, 34]. For both the MC product and its pricing, the presentation of packaged alternatives alongside a la carte offerings affords the MC consumer opportunities to select from simpler consideration sets, resulting in reduced cognitive effort and perceived complexity [34]. MC toolkits enabling the consumer the ability to compare her design to a standard or default version lowered complexity, particularly when the co-designed result came close to her idea of the perfect offering [25].

\subsection{MR features that enhance the co-design experience}

Scholars' work on reactions to virtual or augmented technology indicated positive results in behavioral studies of AR technology in a variety of use situations. Findings yielded similar or improved performance in several arenas, including educational applications used by children; rehabilitation games designed for physical therapy purposes; industrial uses for training manufacturing employees, lowering error rates, or increasing successful, first attempt, task completion; and hand-eye coordination in surgical training $[65,66$, $67,68]$. MR experiences provide several perceived benefits to the consumer. Huang and Liao [58] noted augmented reality interactive technology (ARIT) enables creativity as users "manipulate" offerings or environments; but a variety of aspects of ARIT must accompany the interaction to promote more stimulating experiences in order for the user to derive greater perceived value. Merle et al. [56] asserted VTOs do not, in and of themselves, prompt increased affective or cognitive responses from consumers. Based upon these studies, we surmise that using mobile mechanisms in MR may yield value due to Yang's [57] description of "innovative" users whose interaction with mobile shopping promoted repeated use of shopping on such technologies.

Interactivity is the key characteristic of a mixed reality interface $[11,45,57,58,60]$. Synonymous with collaboration and cooperation, the underlying meaning of interactivity is exchange with someone or something, 
or integration with and between others [11, 46]. The easier it is to collaborate, the more important is seamlessness between how mechanisms or people connect. The physical world delivers reality instantaneously, and the realness of interactivity is integral to the MR experience. Speed and smoothness of response are part of good, interactive technology that promotes "smart interactions" yielding "accuracy" for the user $[46,57]$. The quality of interactivity is important to providing an immersive experience for the consumer. Providers must "think about active and passive ingredients" that form the essence of immersion, specifically those features where the consumer interacts with digitally imbued objects and which are in the background [46].

Visualization is another common element of MR, AR and VR highlighted by scholars, noted earlier as a vital value-inducing characteristic of the $M C$ toolkit, and therefore relevant to our comparison of the $M C$ and $M R$ consumer co-design experiences. Gervautz and Schmalstieg [60] describe AR technology as "deliver[ing] integrated visual experiences directly related to ... [what] ... the user views without any delay." These key characteristics of interactive consumer technology "enrich information in a dynamic way" [46]. By rendering 3D visuals in real time and space, visualization and interactive features are tailor made for enabling a vivid, value rich, MR co-design experience [46].

Virtuality, or virtualization, is another feature of the MR experience [69] representing "presence of elements of virtual reality" [11]. By its nature, VR's computerproduced images, graphics and interface create the unreal but perceptively immersive environments that thoroughly engage the consumer during use [46]. The interaction with the computer, machine or hardware generates telepresence, a feeling that what one sees and how one moves parallels head and limb movements that create "a sense of being at the distant place ... with the body of the machine 'becoming' the body of the human" [69]. As VR and AR are intertwined, the nature of a MC co-design toolkit in MR must incorporate immersive elements.

At the command of the user in the virtual world, customization is inherent in avatars, objects, locations, characterizations, behaviors, time, location, events and more. Many things that trigger the virtual world's goings-on reside in the consumer's ability to "modify behaviors [triggering] the virtual reality system [to alter other conduct] based on changing conditions, such as time of day or the whereabouts of a particular user" [52]. This non-real, virtual environment and its activities can evoke presence, i.e., "acting and feeling that we are in the world created by computer displays" [69], prompting very real affective and cognitive reactions that make structuring a MR co-design toolkit and experience a compelling task. While Merle et al. [56] found VTOs do not necessarily evoke such reactions for apparel websites, their study identified factors related to the consumer's very real body and self-image, which a provider must incorporate into the try-on experience for VR to provoke real reactions.
Studies on the experience in AR address location and mobility characteristics $[11,46,54,60]$. Location is a broader concept beyond specificity of place in which place no longer defines where one is when interacting digitally [54]. For example, an individual could be in an office, at home, on the beach, or in an airplane when preparing or responding to an email. Therefore, the concept of place is what one wants, when and where one wants, a variation on the basic element of what the consumer seeks in $\mathrm{MC}[8,19]$. This poses an interesting component to the design of a MR toolkit. While several technical aspects of location in MR include physical whereabouts related to mapping, signals and location-based suggestions and offerings to consumers, mobility becomes important to the MR codesign process. Though enabling mechanisms determine the type and nature of interaction with a toolkit, MR hardware itself may need to allow free use of a consumer's hands and limbs to utilize and interact with the physical process associated with a MR customized offering. In addition, the trigger and viewing of the augmented environment is confined to a limited area or landscape where - with current technology going outside of these areas results in subjects disappearing from view. Alternatively, restrictions on mobility in the design area could hamper a user's sense of movement and flexibility, which is relatively unrestrained when the MC consumer uses a mouse, wireless or wired, or employs touch, unaided or via styli. The social element of MR is important to the consumer experience, also. MR's interactive nature offers both consumers and providers the opportunity to build relationships with one another, and to do so with other users and with bystanders or those on the periphery during AR activities. Sholtz and Smith [47] describe this characteristic as the "socio-physical" or "sociability" aspect of MR. As noted earlier, user communities and peer input are important feedback elements of the MC co-design toolkit. The essence of these features is social. Given the prominence and ubiquity of social media [60], such characteristics are integral to the future of well-designed MC toolkits. MC scholars underscore the importance of incorporating robust social and sharing mechanisms in co-design toolkits $[63,64]$. The ELSE Corporation's cloud-based platform is a pioneering example of how social interaction has been designed into a MC mixed reality application: ELSE enables a consumer to connect to a friend in realtime. Both converse with each other, sharing feedback as the user customizes her shoes [7].

\section{CONCLUSIONS}

\subsection{MR as a next step in the MC co-design experience}

It would seem that MR is a logical next step when considering the $M C$ co-design experience. Most $M C$ toolkits are enabled by PC or mobile device web interfaces. There are several aspects to consider in toolkit design in MR environments. In a VR co-design situation, the user must take the form of an avatar, whether human-like or not, as the VR experience is of 
an isolating nature in that users are supposed to forget about their surrounding environment and be fully immersed in their virtual worlds. Compared to VR, AR may be better suited for MC toolkit design due to its grounding in the physical world. In addition, developing MR techniques usually revolve around producing extremely realistic augmented images or visualizations with quick rendering times. In $A R$, the experience stops when outside of the AR mechanism's view because the augmented view is limited to a finite area. Haptic aspects may be necessary to enhance the MC codesign experience in MR given one is operating, seeing and responding in real time: beyond rich visualization, a value-laden co-design experience in MR may require further development of sensory inputs to make manipulation of an item more real, e.g. simulating touch or that new-from-the-store scent. In addition, there are a variety of enabling mechanisms that render the MR experience. Mobile devices (smartphones, tablets) goggles, glasses, video screens, sensory gloves, motion-sensing apparel, cameras and hardware, magic mirror, head-mounted displays, and others are utilized in MR. Depending upon the enabling hardware or platform, any of these mechanisms for broad consumer use and adoption is a current constraint likely to be overcome in the near future by technological advances.

\subsection{Contributions to the MC field and future research directions}

This exploratory analysis contributes to the theoretical conversation on future design and development of $\mathrm{MC}$ co-design toolkits in mixed reality. From the managerial perspective, this work offers providers topics to consider in building future co-design experiences that create and capture relational value for consumers via advanced digital and technological offerings.

Though directions for future research are many, we suggest a few that may be integral in delivering valueladen benefits to MC co-design offerings in MR. We considered the consumer experiential values of complexity, control and enjoyment, but further exploration is necessary to ascertain whether these perceptions are the most relevant to consider in designing a mass customization, mixed reality toolkit. Though intentions to use and return are among values cited in the extant literature on MR, aspects of the relational values of satisfaction and loyalty are not addressed in depth. Such may be necessary to determine the extent to which a mixed reality configurator is viable as an enabler of relational benefit in the consumer co-design experience. Also, several scholars note the importance of social connectivity and interaction with other users in MR mechanisms, and the literature could benefit from further examination of the value associated with such relationships. Further, studies in this realm may help enlighten or provide insights into MC experience, MR, and toolkit design in in arenas related to culture, accessibility, sustainability and other human factors important to society.

\section{REFERENCES}

[1] Franke, N. and Piller, F.T. (2003), "Key Research Issues in User Interaction with Configuration Toolkits in a Mass Customization System", International Journal of Technology Management, Vol. 26, No. 5/6, pp. 578-599.

[2] Barba, E., Maclntyre, B. and Mynatt, E. D. (2012), "Here We Are! Where Are We? Locating Mixed Reality in the Age of the Smartphone", Proceedings of the IEEE, Vol. 100, No. 4, pp. 929-936.

[3] Milgram, P. and Kishino, F. (1994), "A Taxonomy of Mixed Reality Visual Displays", IEICE Transactions on Information and Systems, Vol. 77, No. 12, pp. 1321-1329.

[4] Blažek, V., Venema, B., Leonhardt, S. and Blažek, P. (2018), "Customized Optoelectronic In-Ear Sensor Approaches for Unobtrusive Continuous Monitoring of Cardiorespiratory Vital Signs", International Journal of Industrial Engineering and Management, Vol. 9, No. 4, pp. 197-203.

[5] Pine, B. J. and Gilmore, J. H. (2011), The Experience Economy, Harvard Business School Press. Boston, MA, USA.

[6] Gandhi, A., Magar, C. and Roberts, R. (2014), "How Technology Can Drive the Next Wave of Mass Customization", Business Technology Office, pp. 1-8.

[7] McDonald, C. and Golub, A. (2018), "Personalized Digital Last (A Women's Example): The Tool Required to Enable Mass Customization", IEEE Industry Connections, pp. 1-16.

[8] Gilmore, J. H. and Pine, B. J. (2000), Markets of One: Creating Customer-Unique Value through Mass Customization, Harvard Business School Press, Boston, MA, USA.

[9] Chesbrough, H. W. (2006), Open Innovation: The New Imperative for Creating and Profiting from Technology, Harvard Business School Press. Boston, MA, USA.

[10] Christensen, C. M., Cook, S. and Hall, T. (2006), "What Customers Want from Your Products", Harvard Business School Newsletter: Working Knowledge, Boston, MA, USA.

[11] Javornik, A. (2016), "Augmented Reality: Research Agenda for Studying the Impact of Its Media Characteristics on Consumer Behavior", Journal of Retailing and Consumer Services, Vol. 30, pp. 252-261.

[12] Porter, M. E. and Heppelmann, J. E. (2017), "A Manager's Guide to Augmented Reality", Harvard Business Review, Vol. 95, No. 6, pp. 45-57.

[13] Brown, M. and Lubelczyk, M. (2018), The Future of Shopping Centers. A.T. Kearney, Inc., pp. 1-19.

[14] Salvador, F., de Holan, P.M. and Piller, F.T. (2009), "Cracking the Code of Mass Customization", MIT Sloan Management Review, Vol. 50, No. 3, pp. 71-78.

[15] Dellaert, B. G. C. and Dabholkar, P.A. (2009), "Increasing the Attractiveness of Mass Customization: The Role of Complementary Online Services and Range of Options", International Journal of Electronic Commerce, Vol. 13, No. 3, pp. 43-70.

[16] Schreier, M. (2006), "The Value Increment of Mass-Customized Products: An Empirical Assessment", Journal of Consumer Behavior, Vol. 5, No. 4, pp. 317-327.

[17] Suzić, N., Sandrin, E., Suzić, S., Forza, C., Trentin, A. and Anišić, Z. (2018), "Implementation guidelines for mass customization: $A$ researcher-oriented view", International Journal of Industrial Engineering and Management, Vol. 9, No. 4, pp. 229-243.

[18] Davis, S.M. (1987), Future Perfect, Reading, MA: AddisonWesley Publishing Company.

[19] Pine, B. J. (1993), Mass Customization: The New Frontier in Business Competition, Harvard Business School Press, Boston, MA, USA

[20] Tseng, M. and Jiao, J. (1996). Design for Mass Customization, Annals of the CIRP, Vol. 45, No. 6, pp. 153-156.

[21] Franke, N. and Piller, F. T. (2004), "Value Creation by Toolkits for User Innovation and Design: The Case of the Watch Market", Journal of Product Innovation Management, Vol. 21, No. 6, pp. 401-415.

[22] Wind, J. and Rangaswamy, A. (2001), Customerization: The Next Revolution in Mass Customization. Journal of Interactive Marketing, Vol. 15, No. 1, pp. 13-32.

[23] Fiore, A.M., Lee, S.E. and Kunz, G. (2004), "Individual Differences, Motivations, and Willingness to Use a Mass Customization Option for Fashion Products", European Journal of Marketing, Vol. 38, No. 7, pp. 835-849.

[24] Bardacki, A. and Whitelock, J. (2004), "How "Ready" Are Customers for Mass Customisation? An Exploratory Investigation", European Journal of Marketing, Vol. 38, No. 11/12, pp. 1396-1416. 
[25] Dellaert, B. G. C. and Stremersch, S. (2005), "Marketing MassCustomized Products: Striking a Balance between Utility and Complexity", Journal of Marketing Research, Vol. 42, No. 6, pp. 219-227.

[26] Franke, N. and Schreier, M. (2008), "Product Uniqueness as a Driver of Customer Utility in Mass Customization", Marketing Letters, Vol. 19, No. 2, pp. 93-107.

[27] Franke, N., Keinz, P. and Schreier, M. (2008), "Complementing Mass Customization Toolkits with User Communities: How Peer Input Improves Customer Self-Design", Journal of Product Innovation Management, Vol. 25, No. 6, pp. 546-559.

[28] Franke, N. and Schreier, M. (2010), "Why Customers Value Mass-Customized Products: The Importance of Process Effort and Enjoyment", Journal of Product Innovation Management, Vol. 27, No. 12, pp. 1020-1031.

[29] Franke, N., Schreier, M. and Kaiser, U. (2010), "The "I Designed It Myself" Effect In Mass Customization", Management Science, Vol. 56, No. 1, pp. 125-140.

[30] Merle, A., Chandon, J. L., Roux, E. and Alizon, F. (2010) "Perceived Value of the Mass Customized Product and Mass Customization Experience for Individual Consumers", Production and Operations Management, Vol. 19, No. 5, pp. 503-514.

[31] Turner, F. and Merle, A. (2015), "Enhancing the Consumer's Value of the Co-Design Experience in Mass Customization: The Relationship between Perceived Value, Satisfaction, Loyalty Intentions and Thinking Style", 2015 World Conference on Mass Customization, Personalization and Co-Creation: Managing Complexity, Montreal, Quebec, CA.

[32] Trentin, A., Perin, E. and Forza, C. (2014), "Increasing the Consumer-Perceived Benefits of a Mass-Customization Experience through Sales-Configurator Capabilities", Computers in Industry, Vol. 65, No. 4, pp. 693-705.

[33] Trentin, A., Perin, E. and Forza, C. (2013), "Sales configurator capabilities to avoid the product variety paradox: construct development and validation", Computers in Industry, Vol. 64, No. 4, pp. 436-447

[34] Turner, F., Merle, A. and Fatien, P. (2011), "How To Assess and Increase the Value of a Co-Design Experience: A Synthesis of the Extant Literature", 2011 World Conference on Mass Customization, Personalization and Co-Creation, Bridging Mass Customization and Open Innovation, San Francisco, CA, USA.

[35] Sandrin, E. (2017), "Synergic Effects of Sales-Configurator Capabilities on Consumer-Perceived Benefits of MassCustomized Products", International Journal of Industria Engineering and Management, Vol. 8, No. 3, pp. 177-188.

[36] Sandrin, E., Trentin, A., Grosso, C. and Forza, C. (2017) "Enhancing the Consumer-Perceived Benefits of a MassCustomized Product through Its Online Sales Configurator: An Empirical Examination", Industrial Management and Data Systems, Vol. 117, No. 6, pp. 1295-1315.

[37] Reichheld, F. F. and Schefter, P (2000), "E-Loyalty: Your Secret Weapon on the Web", Harvard Business Review, Vol. 78, No. 4, pp 105-113.

[38] Holbrook, M. B. (1999), Consumer Value: A Framework for Analysis and Research, Routledge, New York.

[39] Turner, F. (2018), "The Individualization of Mass Customization: Exploring the Value of Individual Thinking Style through Consumer Neuroscience", in Customization 4.0, Hankammer, S., Nielsen, K., Piller, F. T., Schuh, G., and Wang, N., (eds.), Springer, Cham, DE, pp. 439-450.

[40] Blažek P., Kolb, M., Partl, M. and Streichsbier, C. (2012), "The Usage of Social Media Applications in Product Configurators", International Journal of Industrial Engineering and Management, Vol. 3, No. 4, pp. 179-183

[41] Kudus, S.I.A., Campbell, R.I. and Bibb, R. (2016), "Customer Perceived Value for Self-Designed Personalised Products Made Using Additive Manufacturing", International Journal of Industrial Engineering and Management, Vol. 7, No. 4, pp. 183-193.

[42] Babin, B. J., Darden, W. R. and Griffin, M. (1994), "Work and/or Fun: Measuring Hedonic and Utilitarian Shopping Value", Journal of Consumer Research, Vol. 201, No. 4, pp. 644-656.

[43] Childers, T. L., Christopher, L., Carr, J. P. and Carson, S. (2001), "Hedonic And Utilitarian Motivations For Online Retail Shopping Behavior", Journal of Retailing, Vol. 77, No. 4, pp. 511-520.

[44] Bimber, O. and Raskar, R. (2005), Spatial Augmented Reality: Merging Real and Virtual Worlds, AK Peters/CRC Press, Natick MA, USA.
[45] Azuma, R. T. (1997), "A Survey of Augmented Reality", Presence: Teleoperators and Virtual Environments, Vol. 6, No. 4, pp. 355-385.

[46] Rese, A., Baier, D., Geyer-Schulz, A. and Schreiber, S. (2017) "How Augmented Reality Apps Are Accepted by Consumers: A Comparative Analysis Using Scales and Opinions", Technological Forecasting and Social Change, Vol. 124, pp. 306-319.

[47] Scholz, J. and Smith, A. N. (2016), "Augmented Reality: Designing Immersive Experiences that Maximize Consumer Engagement", Business Horizons, Vol. 59, No. 2, pp. 149-161.

[48] Steuer, J. (1992), "Defining Virtual Reality: Dimensions Determining Telepresence", Journal of Communication, Vol. 42, No. 4, 73-93.

[49] Bryson, S. (1996), "Virtual Reality in Scientific Visualization", Communications of the ACM, Vol. 39, No. 5, pp. 62-71.

[50] Brooks, F. P. (1999), “What's Real About Virtual Reality?”, IEEE Computer Graphics and Applications, Vol. 19, No. 6, 16-27.

[51] Zyda, M. (2005), "From Visual Simulation to Virtual Reality to Games”, Computer, Vol. 38, No. 9, pp. 25-32.

[52] Dalrymple, W. C. and McKinnon, S. (2006), U.S. Patent No. 7,036,082. U.S. Patent and Trademark Office, Washington, DC, USA.

[53] Milgram, S. (1992), "The Individual in a Social World: Essays and Experiments", McGraw-Hill, New York, NY, USA.

[54] Mackay, W. E. (1998), "Augmented Reality: Linking Real And Virtual Worlds: A New Paradigm for Interacting with Computers," in Proceedings of The Working Conference on Advanced Visual Interfaces, Communications of the ACM, pp. 13-21.

[55] Luh, Y. P., Wang, J. B., Chang, J. W., Chang, S. Y. and Chu, C. H. (2013), "Augmented Reality-Based Design Customization of Footwear for Children", Journal of Intelligent Manufacturing, Vol. 24, No. 5, pp. 905-917

[56] Merle, A., Senecal, S. and St-Onge, A. (2012), "Whether and How Virtual Try-On Influences Consumer Responses to an Apparel Web Site", International Journal of Electronic Commerce, Vol. 16, No. 3, pp. 41-64

[57] Yang, K. (2012), "Consumer Technology Traits in Determining Mobile Shopping Adoption: An Application of the Extended Theory Of Planned Behavior", Journal of Retailing and Consumer Services, Vol. 19, No. 5, pp. 484-491.

[58] Huang, T. L. and Liao, S. (2015), "A Model of Acceptance of Augmented-Reality Interactive Technology: The Moderating Role of Cognitive Innovativeness", Electronic Commerce Research, Vol. 15, No. 2, pp. 269-295

[59] Dacko, S. G. (2017), "Enabling Smart Retail Settings Via Mobile Augmented Reality Shopping Apps", Technological Forecasting and Social Change, Vol. 124, pp. 243-256

[60] Gervautz, M. and Schmalstieg, D. (2012), "Anywhere Interfaces Using Handheld Augmented Reality", Computer, Vol. 45, No. 7, pp. 26-31.

[61] Arora, N., Dreze, X., Ghose, A., Hess, J. D., lyengar, R., Jing, B., Joshi, Y.V., Kumar, V., Lurie, N.H., Neslin, S., Sajeesh, S., Su, M., Syam, N.B., Thomas, J. and Zhang, Z. J. (2008), "Putting One-to-One Marketing to Work: Personalization, Customization and Choice", Marketing Letters, Vol. 19, no 3, pp. 305-321.

[62] Fürstner, I., Anišić, Z. and Takács, M. (2012), "Product Configurator Self-Adapting to Different Levels of Customer Knowledge", Acta Polytechnica Hungarica, Vol. 9, No. 4, pp. 129-150.

[63] Blažek, P., Kolb, M., Streichsbier, C. and Honetz, S. (2017), "The Evolutionary Process of Product Configurators", In Managing Complexity, Bellemare, J., Carrier, S., Nielsen, K., and Piller, F. T. (eds.), Springer, Cham, DE, pp. 161-172.

[64] Grosso, C., Forza, C. and Trentin, A. (2017), "Supporting The Social Dimension of Shopping for Personalized Products Through Online Sales Configurators", Journal of Intelligent Information Systems, Vol. 49, No. 1, pp. 9-35.

[65] Juan, M. C., Baños, R., Botella, C., Pérez, D., Alcañiz, M. and Monserrat, C. (2006), "An Augmented Reality System for the Treatment of Acrophobia: The Sense of Presence Using Immersive Photography", Presence: Teleoperators and Virtual Environments, Vol. 15, No. 4, pp. 393-402.

[66] Dunleavy, M., Dede, C. and Mitchell, R. (2009), "Affordances and Limitations of Immersive Participatory Augmented Reality Simulations for Teaching and Learning", Journal of Science Education and Technology, Vol. 18, No. 1, pp. 7-22

[67] Han, J., Jo, M., Hyun, E. and So, H. (2015), "Examining Young Children's Perception toward Augmented Reality-Infused 
Dramatic Play", Educational Technology Research and Development, Vol. 63, No. 3, pp. 455-474.

[68] da Silva Cameirão, M., Bermúdez i Badia, S., Duarte, E. and Verschure, P. F. (2011), "Virtual Reality Based Rehabilitation Speeds Up Functional Recovery of the Upper Extremities After Stroke: A Randomized Controlled Pilot Study in the Acute Phase of Stroke Using the Rehabilitation Gaming System", Restorative Neurology and Neuroscience, Vol. 29, No. 5, 287-298.

[69] Sanchez-Vives, M. V. and Slater, M. (2005), "From Presence to Consciousness through Virtual Reality", Nature Reviews Neuroscience, Vol. 6, No. 4, 332. 